\title{
Is participation in food and income assistance programmes associated with obesity in California adults? Results from a state-wide survey
}

\author{
Cindy W Leung ${ }^{1,2, *}$ and Eduardo Villamor ${ }^{1,2,3,4}$ \\ 'Department of Nutrition, Harvard School of Public Health, Boston, 665 Huntington Avenue, Boston, MA \\ 02115, USA: ${ }^{2}$ Department of Epidemiology, Harvard School of Public Health, Boston, MA, USA: ${ }^{3}$ Department \\ of Environmental Health Sciences, University of Michigan School of Public Health, Ann Arbor, MI, USA: \\ ${ }^{4}$ Department of Epidemiology, University of Michigan School of Public Health, Ann Arbor, MI, USA
}

Submitted 7 January 2010: Accepted 2 June 2010: First published online 12 August 2010

\begin{abstract}
Objective: Public assistance programmes may increase risk of obesity among adults. The current study assessed whether participation in the Supplemental Nutrition Assistance Program (SNAP; formerly the Food Stamp Program), Supplemental Security Income (SSI) or California Work Opportunities and Responsibilities to Kids (CalWorks) was associated with obesity, independent of socio-economic status and food insecurity.

Design: A cross-sectional analysis of the 2007 Adult California Health Interview Survey. Outcome measures included BMI and obesity. Distribution of BMI and prevalence of obesity were compared by participation in each programme, using weighted linear and binomial regression models in which BMI or obesity was the outcome, respectively, and programme participation was the predictor.

Setting: A population survey of various health measures.

Subjects: Non-institutionalized adults ( $n$ 7741) whose household income was $\leq 130 \%$ of the federal poverty level.

Results: The prevalence of obesity was $27 \cdot 4 \%$. After adjusting for sociodemographic characteristics, food insecurity and participation in other programmes, the prevalence of obesity was 30\% higher in SNAP participants (95\% CI 6\%, 59\%; $P=0 \cdot 01$ ) than in non-participants. This association was more pronounced among men than women. SSI participation was related to an adjusted 50\% higher prevalence of obesity ( $95 \% \mathrm{CI}$ $27 \%, 77 \%$; $P<0 \cdot 0001)$ compared with no participation. SNAP and SSI participants also reported higher soda consumption than non-participants of any programme. CalWorks participation was not associated with obesity after multivariable adjustment. Conclusions: Participation in SNAP or SSI was associated with obesity independent of food insecurity or socio-economic status. The suggestion that these associations may be mediated by dietary quality warrants further investigation among low-income populations.
\end{abstract}

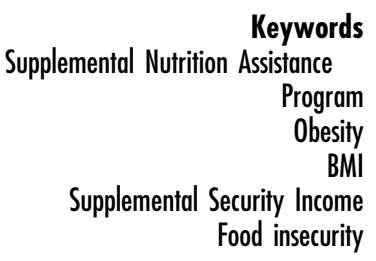

In California, three of the largest public assistance programmes are the Supplemental Nutrition Assistance Program (SNAP), formerly known as the Food Stamp Program (FSP); Supplemental Security Income (SSI); and Temporary Assistance for Needy Families (TANF), also known as California Work Opportunities and Responsibilities to Kids (CalWorks). These programmes have the potential to increase food-purchasing power and improve dietary behaviours among low-income populations. In particular, SNAP has focused on improving access to healthy food through benefits and nutrition education.

SNAP serves households whose monthly gross income is at or less than $130 \%$ of the federal poverty level ${ }^{(1)}$.
In 2007, this threshold was \$US $2237 \cdot 08$ for a family of four. The SSI programme provides benefits to low-income adults aged 65 years or older and to blind or disabled individuals of any age ${ }^{(2)}$. SSI participants are ineligible to receive SNAP benefits because the State of California already adds a monetary supplement to the federal SSI monthly benefits. CalWorks serves deprived families with children aged 18 years or younger, where at least one parent is deceased, disabled, absent from the home or working fewer than 100 hours per month ${ }^{(3)}$. Individuals eligible for either SSI or CalWorks must also have less than \$US 2000 in all resources, including cash, automobiles and land, with some exceptions. 
SNAP benefits may be used to purchase household food items, with the exclusion of alcoholic beverages, dietary supplements, medications and foods hot at the point of sale $^{(4)}$. SSI and CalWorks are both cash-grant programmes, with no restrictions on food purchases. This implied freedom in food choice may have a different effect on beneficiaries in terms of food security status, dietary behaviours and overall health, as compared with SNAP.

The relationship between participation in FSP (SNAP) and obesity among adults has been examined in previous studies, some of which have reported a lack of association ${ }^{(5)}$ whereas others showed a positive association ${ }^{(6-11)}$. Three of the latter studies found stronger associations among women than men ${ }^{(7,9,11)}$. Recently, Zagorsky and Smith demonstrated that participation in FSP (SNAP) was associated with a $1 \mathrm{~kg} / \mathrm{m}^{2}$ greater BMI among women, when compared with non-participants of the same socio-economic characteristics $^{(11)}$. This observed effect of SNAP participation on obesity might be modified by food insecurity. Studies have shown that household food insecurity could be related to obesity ${ }^{(12)}$, especially among women ${ }^{(8,13-18)}$. Associations between participation in other programmes including SSI and CalWorks and obesity have not been previously explored.

The present study aimed to examine how participation in SNAP, SSI or CalWorks was associated with BMI and obesity among their beneficiaries in a large, representative sample of low-income adults, and whether this association was modified by food insecurity or gender. A secondary aim was to examine if programme participation was related to dietary intake of specific foods, which could contribute to explain the associations between programme participation and obesity.

\section{Subjects and methods}

\section{Study population}

We used data from the 2007 California Health Interview Survey (CHIS), a population-based, random-digit-dial (RDD) telephone survey of households aimed to be representative of California's non-institutionalized population. CHIS has been conducted every two years since 2001 and all data sets are publicly available (http:// www.chis.ucla.edu/). We used data from the 2007 CHIS in order to avoid secular effects due to changes in the prevalence of obesity, and to present the most recent findings on the effects of food and income assistance programmes as these would be most relevant from a public health policy perspective. CHIS employed a twostage sample design among the state's forty-four geographic sampling strata. Within each stratum, residential and cellular telephone numbers were dialled and, within each household, one adult ( $\geq 18$ years) was selected to complete the Adult Questionnaire. Interviews were conducted in English, Spanish, Chinese (Mandarin and
Cantonese dialects), Vietnamese and Korean. Proxy interviews by a spouse/partner or adult child were allowed for persons over 65 years of age. The response rate for CHIS was a product of the screener completion rate and the extended interview completion rate. In 2007 , the overall adult response rate was $18 \cdot 3 \%{ }^{(19)}$.

The 2007 CHIS Public Use Files included eighty replicate weights and one final weight to provide valid estimations of variance without the need for geographical strata information, as well as to account for the different sampling probabilities and to adjust for potential nonresponse biases ${ }^{(20)}$. When using the replicate and final weights together, it can be assumed that the estimates and variances obtained from the 51048 completed adult responses are representative of 26873738 California adults living in households.

The analytical sample was restricted to 7741 adults whose household incomes fell at or below $130 \%$ of the federal poverty level, in order to exclude adults who may be ineligible to receive SNAP benefits or to answer questions regarding public programme participation and food insecurity. While one of the eligibility criteria for SSI is being of age 65 years or older, we did not exclude subjects in our sample because a large proportion of SSI beneficiaries (67\%) were under 65 years old. The weighted analytical sample consisted of 5295856 adults. Data were collected from 20 June 2007 to 3 March $2008^{(21)}$.

\section{End points}

The outcomes for analyses were BMI and obesity. BMI was calculated from self-reported height and weight data as $\mathrm{kg} / \mathrm{m}^{2}$. Obesity was defined as BMI $\geq 30 \cdot 0 \mathrm{~kg} / \mathrm{m}^{2}$.

\section{Definition of exposures}

SNAP participation was defined as answering 'yes' to the survey's question 'Are you receiving food stamp benefits?' SSI participation was defined as answering 'yes' to 'Are you receiving SSI?' CalWorks participation was defined as answering 'yes' to 'Are you now receiving TANF or CalWorks?'

Food insecurity was measured using the US Department of Agriculture (USDA) Household Food Security Survey Module: Six-Item Short Form ${ }^{(22)}$, a reliable substitute for the full eighteen-item US Household Food Security Survey Module when it cannot be implemented. The advantages of the short form are that it poses less respondent burden and produces estimates of food insecurity with minimal bias as compared with the eighteen-item module. The disadvantages are that it cannot capture the most severe levels of food insecurity, does not include questions about children in the household, and is somewhat less reliable than fuller modules. Responses of 'sometimes true', 'often true', 'almost every month', 'some months but not every month' and 'yes' were coded as affirmative. A raw score ranging from 0 to 6 was generated by summing the affirmatives of the questions. Food insecurity was classified 
according to the USDA guidelines: 0 or 1 , low or moderate food insecurity; $2-4$, high food insecurity; 5 or 6 , very high food insecurity.

Dietary information collected by the survey included the frequency of consumption of French fries; fruits excluding fruit juice; vegetables excluding fried potatoes; soda excluding diet soda; and fast food. Consumption was measured in times during the week prior to the survey.

Demographic information collected by the survey included age, gender, race, place of birth, education level, household size, smoking status, number of cigarettes smoked per day and health insurance status. Age of the respondent was recoded into four categories (18-29 years, 30-49 years, 50-69 years, $\geq 70$ years). For race, American Indian/Alaskan Native and Pacific Islander categories were collapsed into the Other single/multiple race category. Education level was recoded into four categories $(<12$ years, high-school diploma, some college, bachelor's degree or higher). Household size was recoded into three categories ( 1 or 2 persons, $3-5$ persons, $\geq 6$ persons).

\section{Statistical analysis}

We first examined the associations between potential sociodemographic confounders, including food insecurity, and the prevalence of obesity. Next, we compared the distribution of BMI and the prevalence of obesity by participation in each programme, using weighted linear or binomial regression models in which BMI or obesity was the outcome, respectively, and programme participation was the predictor. Estimates were obtained by fitting multivariate models that included age (18-29 years as reference), sex (male as reference), race (non-Hispanic white as reference), place of birth (US-born as reference), education level $(<12$ years as reference), household size ( 1 or 2 persons as reference), smoking status (never smoker as reference), number of cigarettes smoked per day, health insurance status (insured all past 12 months as reference) and food insecurity (low or moderate food insecurity as reference) as covariates. Robust estimates of the variance were used in all models. We examined whether food insecurity or gender modified the associations between programme participation and BMI by introducing into the model a cross-product term between each of the potential modifiers and programme participation; statistical significance of this interaction term was determined with the Wald test. The association between programme participation and obesity was significantly modified by gender; thus, we fitted multivariate models separately for males and females. Finally, we compared the distribution of intake of selected foods and food groups by participation in programmes with the use of multivariate linear regression models. All statistical tests were two-sided and significance was considered at $P<0 \cdot 05$. Statistical analyses were performed using the statistical software package Stata/IC $10 \cdot 1$ for Windows (StataCorp LP, College Station, TX, USA).

\section{Results}

In the weighted sample of 5295856 adults, $27 \cdot 4 \%$ were obese. Prevalence rates of obesity were highest among adults aged 30-49 years, of African-American descent, born in the USA, with less than 12 years of formal education, living in a household with six or more persons, who were former smokers and of very high food insecurity (Table 1).

Twenty-five per cent of adults reported receiving assistance from any of the three programmes. Participation rates were highest for SNAP $(13 \cdot 3 \%)$, followed by SSI $(12 \cdot 9 \%)$ and CalWorks $(7 \cdot 2 \%)$. SNAP participants had a $1 \cdot 1 \mathrm{~kg} / \mathrm{m}^{2}$ higher adjusted BMI than non-participants $(P=0 \cdot 06$; Table 2$)$. SSI participants also had a $1.8 \mathrm{~kg} / \mathrm{m}^{2}$ higher adjusted BMI $(P<0 \cdot 0001)$ when compared with non-participants. Participation in either SNAP or SSI was positively associated with obesity. After adjustment for sociodemographic characteristics, food insecurity and participation in other programmes, the adjusted prevalence of obesity was $30 \%$ higher among SNAP participants $(P=0 \cdot 01)$ and $50 \%$ higher among SSI participants $(P<0 \cdot 0001)$ compared with non-participants. No association was observed between CalWorks participation and obesity after adjusting for participation in the other public assistance programmes.

Some adults reported receiving benefits from multiple programmes, with the largest overlap occurring between CalWorks and SNAP: $82 \%$ of CalWorks recipients reported receiving SNAP benefits in 2007 . In our sample, 549 adults participated in two or more programmes and 2023 adults participated in only one programme. We examined whether participating in two or more programmes was associated with BMI or obesity compared with participation in only one programme, in this subset of 2572 respondents who participated in at least one programme. After adjustment for sociodemographic characteristics and food insecurity, there was no significant difference in BMI ( $P=0.46)$ or obesity prevalence $(P=0 \cdot 49)$ comparing multiple programme participants with single programme participants.

We next examined whether the associations with SNAP or SSI participation and obesity were modified by food insecurity or gender. Among SNAP participants, 28.7\% reported high food insecurity and another $23 \cdot 2 \%$ reported very high food insecurity. Among SSI participants, $24.5 \%$ reported high food insecurity and $18.5 \%$ reported very high food insecurity. There was no evidence of significant modification by food insecurity of the association between participation in SNAP ( $P$, test for interaction $=0 \cdot 10)$ or SSI $(P$, test for interaction $=0 \cdot 84)$ and the prevalence of obesity. However, the association between participation in SNAP and obesity was stronger in men than women ( $P$, test for interaction $=0 \cdot 01$; Table 3 ). Men who received SNAP benefits had a $2.5 \mathrm{~kg} / \mathrm{m}^{2}$ higher BMI $(P=0.003)$ and a $61 \%$ higher prevalence of obesity 
Table 1 Distributions of BMI and obesity $\left(B M I \geq 30 \cdot 0 \mathrm{~kg} / \mathrm{m}^{2}\right)$ according to sociodemographic characteristics of adults under $130 \%$ of the federal poverty level: California Health Interview Survey, 2007

\begin{tabular}{|c|c|c|c|c|c|c|c|}
\hline & \multirow[b]{2}{*}{$N^{*}$} & \multirow[b]{2}{*}{ Weighted \% } & \multirow[b]{2}{*}{ SE } & \multicolumn{2}{|c|}{ BMI $\left(\mathrm{kg} / \mathrm{m}^{2}\right)$} & \multicolumn{2}{|c|}{ Obesity } \\
\hline & & & & Mean & SE & Weighted \% & SE \\
\hline \multicolumn{8}{|l|}{ Age (years) } \\
\hline $18-29$ & 1345 & $30 \cdot 3$ & 0.8 & $25 \cdot 8$ & 0.2 & $19 \cdot 2$ & $1 \cdot 6$ \\
\hline $30-49$ & 2422 & $39 \cdot 1$ & $0 \cdot 8$ & $29 \cdot 0$ & $0 \cdot 3$ & $34 \cdot 5$ & $1 \cdot 6$ \\
\hline $50-69$ & 2407 & $20 \cdot 7$ & 0.6 & $28 \cdot 1$ & 0.2 & $29 \cdot 2$ & $1 \cdot 4$ \\
\hline$\geq 70$ & 1567 & $9 \cdot 9$ & 0.4 & $26 \cdot 4$ & 0.2 & $20 \cdot 2$ & $1 \cdot 6$ \\
\hline$P$ for trendt & & & & \multicolumn{2}{|c|}{$<0.001$} & \multicolumn{2}{|c|}{0.03} \\
\hline \multicolumn{8}{|l|}{ Gender } \\
\hline Male & 2599 & $42 \cdot 6$ & $1 \cdot 0$ & $27 \cdot 6$ & 0.2 & $26 \cdot 7$ & $1 \cdot 4$ \\
\hline Female & 5142 & $57 \cdot 4$ & $1 \cdot 0$ & $27 \cdot 5$ & 0.2 & $27 \cdot 9$ & 0.9 \\
\hline Pt & & & & \multicolumn{2}{|c|}{$0 \cdot 88$} & \multicolumn{2}{|c|}{0.52} \\
\hline \multicolumn{8}{|l|}{ Raceł } \\
\hline Non-Hispanic white & 3073 & $20 \cdot 8$ & 0.5 & $26 \cdot 9$ & 0.3 & $25 \cdot 5$ & $1 \cdot 6$ \\
\hline Latino/Hispanic & 2178 & $42 \cdot 6$ & $1 \cdot 0$ & $28 \cdot 3$ & 0.2 & $30 \cdot 5$ & $1 \cdot 5$ \\
\hline Asian & 792 & $11 \cdot 4$ & 0.5 & $23 \cdot 8$ & 0.3 & $8 \cdot 0$ & 1.9 \\
\hline African-American & 563 & $7 \cdot 3$ & 0.5 & $29 \cdot 3$ & $0 \cdot 6$ & $37 \cdot 4$ & $3 \cdot 6$ \\
\hline Other single/multiple race & 1135 & $17 \cdot 9$ & 0.9 & $28 \cdot 2$ & 0.4 & $30 \cdot 2$ & $2 \cdot 2$ \\
\hline $\mathrm{Pt}$ & & & & \multicolumn{2}{|c|}{$<0.001$} & \multicolumn{2}{|c|}{$<0.001$} \\
\hline \multicolumn{8}{|l|}{ Birthplace } \\
\hline US-born & 4499 & $42 \cdot 7$ & $0 \cdot 8$ & $27 \cdot 7$ & 0.2 & $30 \cdot 8$ & $1 \cdot 5$ \\
\hline Foreign-born & 3242 & $57 \cdot 3$ & 0.8 & $27 \cdot 5$ & 0.2 & $24 \cdot 8$ & $1 \cdot 1$ \\
\hline$P+$ & & & & \multicolumn{2}{|c|}{0.36} & \multicolumn{2}{|c|}{0.002} \\
\hline \multicolumn{8}{|l|}{ Education level } \\
\hline$<12$ years & 2520 & $44 \cdot 7$ & $0 \cdot 7$ & $28 \cdot 4$ & 0.2 & $31 \cdot 4$ & $1 \cdot 4$ \\
\hline High-school diploma & 2383 & $30 \cdot 8$ & 0.8 & $27 \cdot 0$ & 0.3 & $24 \cdot 7$ & 0.2 \\
\hline Some college & 1839 & $15 \cdot 7$ & 0.6 & $27 \cdot 4$ & $0 \cdot 3$ & $27 \cdot 2$ & $1 \cdot 6$ \\
\hline Bachelor's degree or higher & 999 & $8 \cdot 8$ & 0.5 & $25 \cdot 6$ & 0.3 & $16 \cdot 3$ & $2 \cdot 2$ \\
\hline$P$ for trendt & & & & \multicolumn{2}{|c|}{$<0.001$} & \multicolumn{2}{|c|}{$<0.001$} \\
\hline \multicolumn{8}{|l|}{ Household size } \\
\hline 1 or 2 persons & 4027 & $26 \cdot 0$ & $0 \cdot 7$ & $27 \cdot 0$ & 0.2 & $25 \cdot 5$ & $1 \cdot 3$ \\
\hline $3-5$ persons & 2918 & $51 \cdot 3$ & $1 \cdot 1$ & $27 \cdot 4$ & 0.2 & $25 \cdot 7$ & $1 \cdot 3$ \\
\hline$\geq 6$ persons & 796 & $22 \cdot 7$ & $1 \cdot 1$ & $28 \cdot 5$ & 0.4 & $33 \cdot 2$ & $2 \cdot 1$ \\
\hline$P$ for trendt & & & & & & 0.00 & \\
\hline Smoking status & & & & & & & \\
\hline Never smoked regularly & 4461 & $64 \cdot 6$ & 0.9 & $27 \cdot 4$ & 0.2 & $26 \cdot 0$ & $1 \cdot 1$ \\
\hline Quit smoking & 1773 & $17 \cdot 3$ & $0 \cdot 7$ & $28 \cdot 2$ & $0 \cdot 3$ & $30 \cdot 7$ & $1 \cdot 8$ \\
\hline Currently smokes & 1507 & $18 \cdot 1$ & 0.9 & $27 \cdot 6$ & 0.4 & $29 \cdot 1$ & $2 \cdot 2$ \\
\hline$P$ for trendt & & & & & & 0.06 & \\
\hline Health insurance status & & & & & & & \\
\hline Insured all past 12 months & 5471 & $58 \cdot 1$ & $1 \cdot 0$ & $27 \cdot 5$ & 0.2 & $27 \cdot 5$ & $1 \cdot 0$ \\
\hline Uninsured any past 12 months & 484 & $7 \cdot 3$ & 0.6 & $27 \cdot 6$ & 0.5 & $28 \cdot 6$ & $3 \cdot 5$ \\
\hline Currently uninsured & 1786 & $34 \cdot 6$ & 0.9 & $27 \cdot 6$ & 0.2 & $26 \cdot 8$ & $1 \cdot 5$ \\
\hline$P$ for trendt & & & & & & 0.32 & \\
\hline Food insecurity§ & & & & & & & \\
\hline Moderate food insecurity & 4888 & $62 \cdot 2$ & $1 \cdot 1$ & $27 \cdot 0$ & 0.2 & $24 \cdot 6$ & $1 \cdot 1$ \\
\hline High food insecurity & 1772 & $24 \cdot 7$ & $1 \cdot 0$ & $28 \cdot 3$ & 0.3 & $30 \cdot 4$ & 1.9 \\
\hline Very high food insecurity & 1081 & $13 \cdot 1$ & 0.6 & $28 \cdot 9$ & 0.4 & $34 \cdot 8$ & $2 \cdot 8$ \\
\hline$P$ for trendt & & & & & & $<0.0$ & \\
\hline
\end{tabular}

${ }^{*}$ Crude $n: 7741$; weighted $n: 5295856$.

tFor a variable representing the ordinal categories that was introduced into a univariate linear regression model as a continuous predictor. For gender and birthplace, $P$ is from a Wald test.

‡'Other single/multiple race' includes American Indian/Alaskan Native, Pacific Islander and persons of multiple races/ethnicities.

§From US Department of Agriculture's Food Security Survey Module: Six-Item Short Form. Low or moderate food insecurity defined as a score of 0 or 1 ; high food insecurity defined as a score of 2-4; very high food insecurity defined as a score of 5 or 6 .

$(P=0 \cdot 002)$ than men who did not receive SNAP benefits, after adjusting for age (18-29 years as reference), race, place of birth, education level, household size, health insurance status, smoking status, number of cigarettes smoked per day, food insecurity and participation in other public assistance programmes. By contrast, women who received SNAP benefits did not have a significantly different BMI $(P=0 \cdot 86)$ or obesity prevalence $(P=0 \cdot 43)$ compared with women did not receive these benefits.
Last, we examined the intake frequencies of certain foods and food groups consumed during the week prior to the survey in relation to programme participation, as this might help to explain whether the associations between programme participation and obesity could be mediated in part through different food choices (Fig. 1). After adjustment for sociodemographic characteristics and food insecurity, soda consumption was significantly higher among both SNAP and SSI participants as compared 
Table 2 Participation in public assistance programmes and associations with BMI and obesity $\left(\mathrm{BMI} \geq 30 \cdot 0 \mathrm{~kg} / \mathrm{m}^{2}\right)$ among adults under $130 \%$ of the federal poverty level: California Health Interview Survey, 2007

\begin{tabular}{|c|c|c|c|c|c|c|c|c|c|c|c|}
\hline & \multirow[b]{2}{*}{$N^{*}$} & \multirow[b]{2}{*}{ Weighted \% } & \multirow[b]{2}{*}{ SE } & \multicolumn{4}{|c|}{ BMI $\left(\mathrm{kg} / \mathrm{m}^{2}\right)$} & \multicolumn{4}{|c|}{ Obesity } \\
\hline & & & & Mean & SE & $\begin{array}{l}\text { Adjusted } \\
\text { difference }\end{array}$ & $95 \% \mathrm{Cl}$ & Weighted \% & SE & $\begin{array}{c}\text { Adjusted } \\
\text { prevalence ratio }\end{array}$ & $95 \% \mathrm{Cl}$ \\
\hline \multicolumn{12}{|l|}{ SNAP } \\
\hline Non-participants & 6737 & $86 \cdot 7$ & 0.7 & $27 \cdot 3$ & $0 \cdot 1$ & Ref. & - & $25 \cdot 9$ & 0.9 & Ref. & - \\
\hline Participants & 1004 & $13 \cdot 3$ & $0 \cdot 7$ & $29 \cdot 1$ & 0.6 & $1 \cdot 08 t$ & $-0 \cdot 05,2 \cdot 22$ & $36 \cdot 6$ & 0.3 & $1 \cdot 30 t$ & $1 \cdot 06,1.59$ \\
\hline \multicolumn{12}{|l|}{ SSI } \\
\hline Non-participants & 6078 & $87 \cdot 1$ & 0.6 & $27 \cdot 3$ & $0 \cdot 1$ & Ref. & - & $25 \cdot 7$ & 0.9 & Ref. & - \\
\hline Participants & 1663 & $12 \cdot 9$ & 0.6 & $29 \cdot 1$ & 0.5 & $1 \cdot 83 t$ & $0 \cdot 89,2 \cdot 78$ & $38 \cdot 8$ & $2 \cdot 7$ & $1 \cdot 50 t$ & $1 \cdot 27,1 \cdot 77$ \\
\hline \multicolumn{12}{|l|}{ CalWorks } \\
\hline Non-participants & 7216 & $92 \cdot 8$ & 0.5 & $27 \cdot 4$ & $0 \cdot 1$ & Ref. & - & $26 \cdot 9$ & 0.9 & Ref. & - \\
\hline Participants & 525 & $7 \cdot 2$ & 0.5 & $29 \cdot 1$ & 0.7 & $0 \cdot 16+$ & $-1 \cdot 07,1 \cdot 40$ & $33 \cdot 4$ & $3 \cdot 5$ & $0.84 t$ & $0.66,1.07$ \\
\hline
\end{tabular}

SNAP, Supplemental Nutrition Assistance Program (formerly the Food Stamp Program); SSI, Supplemental Security Income; CalWorks, California Work Opportunities and Responsibilities to Kids; Ref., reference category.

${ }^{*}$ Crude $n: 7741$; weighted $n: 5295856$.

tFrom linear (BMI as continuous outcome) or binomial (obesity as dichotomous outcome) regression models adjusted for age (18-29 years as reference), sex (male as reference), race (non-Hispanic white as reference), place of birth (US-born as reference), education level ( $<12$ years as reference), household size ( 1 or 2 persons as reference), health insurance status (insured all past 12 months as reference), smoking status (never smoker as reference), number of cigarettes smoked per day, food insecurity (low or moderate food insecurity as reference) and participation in other public assistance programmes

Table 3 Participation in SNAP and associations with BMI and obesity $\left(\mathrm{BMI} \geq 30 \cdot 0 \mathrm{~kg} / \mathrm{m}^{2}\right)$ by gender among adults under $130 \%$ of the federal poverty level: California Health Interview Survey, 2007

\begin{tabular}{|c|c|c|c|c|c|c|c|c|c|c|c|}
\hline & \multirow[b]{2}{*}{$N^{*}$} & \multirow[b]{2}{*}{ Weighted \% } & \multirow[b]{2}{*}{ SE } & \multicolumn{4}{|c|}{ BMI $\left(\mathrm{kg} / \mathrm{m}^{2}\right)$} & \multicolumn{4}{|c|}{ Obesity } \\
\hline & & & & Mean & SE & $\begin{array}{l}\text { Adjusted } \\
\text { difference }\end{array}$ & $95 \% \mathrm{Cl}$ & Weighted \% & SE & $\begin{array}{c}\text { Adjusted } \\
\text { prevalence ratio }\end{array}$ & $95 \% \mathrm{Cl}$ \\
\hline \multicolumn{12}{|l|}{ Male } \\
\hline SNAP non-participants & 2335 & $90 \cdot 2$ & $1 \cdot 0$ & $27 \cdot 3$ & 0.2 & Ref. & - & $24 \cdot 7$ & $1 \cdot 4$ & Ref. & - \\
\hline SNAP participants & 264 & $9 \cdot 8$ & $1 \cdot 0$ & $30 \cdot 0$ & $0 \cdot 7$ & $2 \cdot 47 t$ & $0.85,4.09$ & $44 \cdot 5$ & $4 \cdot 8$ & $1 \cdot 61+$ & $1 \cdot 20,2 \cdot 16$ \\
\hline \multicolumn{12}{|l|}{ Female } \\
\hline SNAP non-participants & 4402 & $84 \cdot 1$ & $1 \cdot 0$ & $27 \cdot 3$ & 0.2 & Ref. & - & $26 \cdot 9$ & $1 \cdot 2$ & Ref. & - \\
\hline SNAP participants & 740 & $15 \cdot 9$ & $1 \cdot 0$ & $28 \cdot 7$ & $0 \cdot 7$ & $0 \cdot 13 t$ & $-1 \cdot 30,1 \cdot 56$ & $33 \cdot 0$ & $3 \cdot 2$ & $1 \cdot 10 t$ & $0.86,1 \cdot 41$ \\
\hline
\end{tabular}

SNAP, Supplemental Nutrition Assistance Program (formerly the Food Stamp Program); Ref., reference category.

${ }^{*}$ Crude $n: 7741$; weighted $n: 5295856$

tFrom linear (BMI as continuous outcome) or binomial (obesity as dichotomous outcome) regression models adjusted for age (18-29 years as reference), sex (male as reference), race (non-Hispanic white as reference), place of birth (US-born as reference), education level ( $<12$ years as reference), household size (1 or 2 persons as reference), health insurance status (insured all past 12 months as reference), smoking status (never smoker as reference), number of cigarettes smoked per day, food insecurity (low or moderate food insecurity as reference) and participation in other public assistance programmes. Models were run separately for males and females.

with non-participants of any programme $(P=0.02$ for SNAP; $P=0.02$ for SSI). SSI participants also reported greater fruit consumption than non-participants. Intake frequencies of vegetables, French fries and fast food did not differ by public programme participation.

\section{Discussion}

Our study results indicate that participation in SNAP or SSI is associated with obesity, independent of food insecurity or participation in other public assistance programmes. These findings are consistent with previous studies that have demonstrated a positive relationship between SNAP participation and obesity ${ }^{(8-11)}$, although they suggest that these associations may also apply to SSI participants. Due to dual participation, the association between participation in CalWorks and obesity was strongly attenuated after adjusting for participation in SNAP.
Researchers have attributed the association between SNAP participation and obesity to the 'food stamp cycle', a cycle where monthly receipt of SNAP benefits may encourage periods of binge eating followed by energy restriction among its participants ${ }^{(5,8,10,23)}$. Continuous exposure to the 'food stamp cycle' may subsequently increase fat accumulation and promote obesity ${ }^{(24)}$. Although SSI is a cash benefits programme rather than a food assistance programme, it is possible that SSI recipients also experience a similar cycle of food availability followed by energy restriction, as both programmes issue their benefits monthly. An alternative hypothesis to explain the association between SSI and obesity is reverse causation as obese persons are more likely to be considered disabled than non-obese persons. While the Social Security Administration does not specifically recognize obesity as a disability, persons with medical documentation of severe obesity that impairs their work capacity could qualify for SSI benefits. Furthermore, 


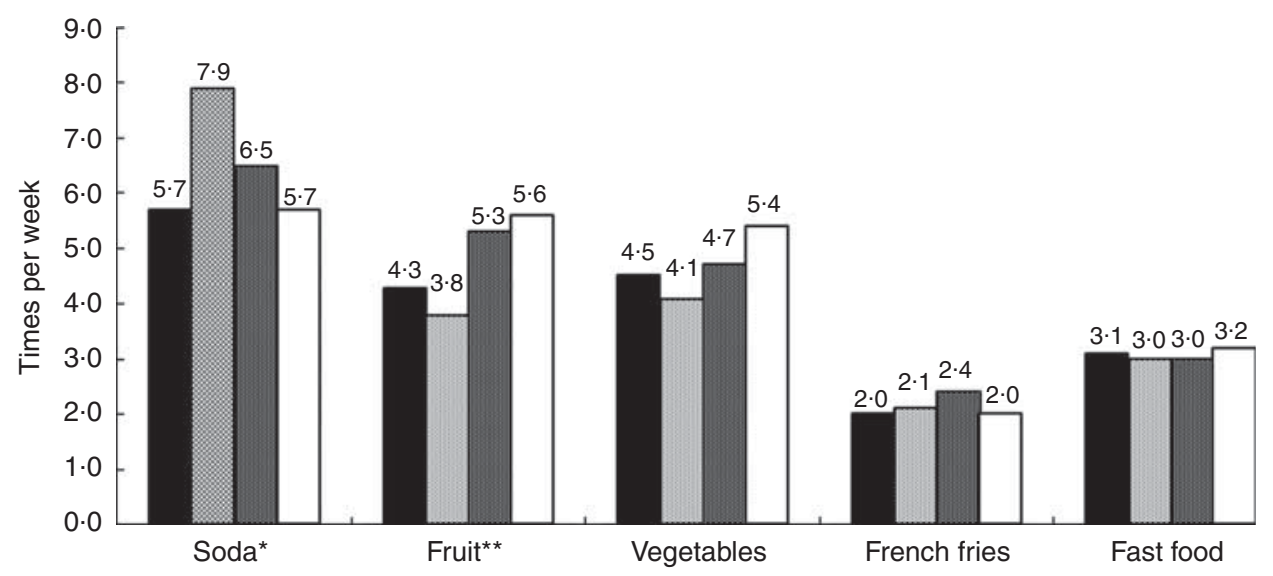

Fig. 1 Adjusted mean weekly intakes of selected foods and food groups among SNAP participants ( $\square$ ), SSI participants ( $\square$ ), CalWorks participants $(\square)$ and non-participants of any programme ( $\square$ ): California Health Interview Survey 2007. SNAP, Supplemental Nutrition Assistance Program (formerly the Food Stamp Program); SSI, Supplemental Security Income; CalWorks, California Work Opportunities and Responsibilities to Kids. Model adjusted for age (18-29 years as reference), sex (male as reference), race (non-Hispanic white as reference), place of birth (US-born as reference), education level ( $<12$ years as reference), household size ( 1 or 2 persons as reference), health insurance status (insured all past 12 months as reference), smoking status (never smoker as reference), number of cigarettes smoked per day and food insecurity (low or moderate food insecurity as reference). "Weekly intake frequencies of soda were significantly different: $P=0.01$ for SNAP participants $v$. non-participants of any programme; $P=0.03$ for SSI participants $v$. non-participants of any programme. ${ }^{*}$ Weekly intake frequencies of fruit were significantly different: $P=0.04$ for SSI participants $v$. non-participants of any programme

persons with health conditions or impairments caused or exacerbated by obesity, including cardiovascular (e.g. IHD), endocrine (e.g. diabetes mellitus) and respiratory conditions (e.g. sleep-related breathing disorders), could also qualify for SSI benefits. For these reasons, it is possible that the relationship between SSI and obesity is not mediated through diet, but that obese persons are more likely to receive SSI benefits based on their existing health conditions.

Several observational studies have identified an association between food insecurity and obesity ${ }^{(15-18,25)}$ and it is possible that food insecurity may drive the associations between participating in SNAP or SSI and obesity. Our study showed that SNAP and SSI recipients have high rates of food insecurity and therefore may be more susceptible to the effects of poverty on dietary intake. Mechanisms for this association were proposed by Drewnowski and Specter ${ }^{(26)}$ : inverse associations between energy density and food costs can encourage food-insecure individuals to increase purchases of energy-dense foods. This behaviour is then reinforced by the high palatability of excess sugar and fats, which leads to higher energy intake. However, food insecurity did not appear to modify the associations between SNAP or SSI and obesity, suggesting that associations with obesity might be due to programme-specific effects.

In our study, we observed significantly higher soda consumption among SNAP and SSI participants than nonparticipants. Studies have shown that poverty-stricken individuals are less likely to live in neighbourhoods with access to supermarkets ${ }^{(27)}$ and more likely to have access to convenience stores or fast-food restaurants ${ }^{(28,29)}$. For SNAP and SSI participants, it is possible that the monthly benefits encourage consumption of inexpensive, highenergy foods, rather than improve dietary behaviours and reduce total energy intake. For example, Cason et al. ${ }^{(30)}$ showed that FSP (SNAP) participants had significantly higher intakes of total fat and total energy than FSP nonparticipants. Other studies also found that meat products were of high importance to FSP (SNAP) participants ${ }^{(31,32)}$. While these results suggest that certain dietary behaviours may play a role in the associations between programme participation and obesity, other factors like physical inactivity may also contribute to this relationship.

Interestingly, the association between participation in SNAP and obesity appeared to be stronger in men than women. This finding appears to contradict previous studies that showed stronger associations among women ${ }^{(7,9,11)}$. However, a report by Baum found that long-term participation in the FSP (SNAP) was associated with a $10 \%$ increase in obesity among females and a $15 \%$ increase in obesity among males ${ }^{(6)}$. Because the survey did not collect information on duration of participation in each public assistance programme, it is possible that, on average, men have longer participation than women. Another possibility is misclassification of BMI and obesity prevalences due to the self-reported nature of height and weight data. If women are more likely to under-report their weight than men ${ }^{(33,34)}$, then any association between programme participation and BMI or obesity could be attenuated for women, as we observed in our study. Furthermore, men may have less influence on how SNAP benefits are used to purchase food items while simultaneously consuming a larger proportion of the household food than women. Men who participate in SNAP may also be more likely to 
consume some meals outside the home due to their occupation, which could be correlated to higher energy intake. Combined with greater access to less healthful food options through SNAP, it is possible that men participating in SNAP are more prone to increased BMI and obesity compared with their non-participant counterparts.

The main limitation of the present study is the crosssectional nature of the design. It is not possible to address temporality of the observed associations or to make inferences about causation. A second limitation is the representativeness of the study sample. While the CHIS sample is meant to characterize California's diverse adult population, certain adults at higher need of public assistance or at higher risk of obesity may have been excluded from the original survey design. These include adults without landlines or cellular phones, adults in institutionalized settings and adults without a permanent residence (e.g. homeless or persons residing in shelters).

The overall adult response rate of $18 \cdot 3 \%$ was lower than the CHIS response rates from previous years, but consistent with a general decline in response rates observed in other RDD telephone state-wide surveys ${ }^{(19)}$. When compared with the 2007 California Behavioral Risk Factor Surveillance System (BRFSS), its overall response rate of $24 \cdot 1 \%$ was slightly higher than the response rate from CHIS, but comparable given that the CHIS was more conservative in its calculation of response rates than BRFSS. Because the CHIS sample was weighted to reflect California's demographic distributions, it is unlikely that the low response rate significantly affected the generalizability of the findings.

The use of self-reported data, especially self-reported height and weight data, may have underestimated the true BMI of study subjects, which might have decreased precision in the observed associations between public programme participation and obesity ${ }^{(35)}$. Our analysis found that $27 \cdot 8 \%$ of low-income adults in our study population were obese. This figure is slightly lower than the national figure of $33 \cdot 8 \%$ estimated by Flegal et al. using National Health and Nutrition Examination Survey data for $2007-2008^{(36)}$. This is expected since California is known to have lower rates than the national average ${ }^{(37)}$, possibly due to a state culture that facilitates healthy eating and physical activity. Furthermore, BMI is an imperfect measure of adiposity because it cannot differentiate between lean body mass and fat mass ${ }^{(38)}$. Future studies that examine the effects of public programme participation should include measures of central adiposity, including waist circumference, as a secondary outcome ${ }^{(39)}$. Another potential limitation may include the application of the SNAP eligibility criterion to other programmes that may serve individuals of different demographics. However, both SSI and CalWorks have similar limits on financial resources and the data set did not provide enough information to apply further programme-specific criteria. Lastly, the food intake component of the questionnaire was limited in its ability to assess dietary intake. Without more accurate measures of individual foods and nutrients, it would be difficult to assess the role of diet in the association between participation in SNAP or SSI and obesity.

In conclusion, these results suggest that participation in the SNAP or SSI is associated with obesity, independent of food insecurity and socio-economic status. The relationship between participation in SNAP and obesity prevalence was stronger in men than in women, suggesting that men are not immune to the relationship between participation in SNAP and obesity as had been previously suggested by other studies. In order to better understand the relationship between public programme participation and obesity, longitudinal studies of the effects of individual programmes with strong dietary assessment methods are needed. If these associations are truly causal, then programmatic changes may help in alleviating the risk of obesity among low-income men and women participating in these public assistance programmes.

\section{Acknowledgements}

The authors did not receive any financial support for this project and have no conflicts of interest to declare. C.W.L. developed the analytic strategy, conducted the statistical analysis and wrote the initial manuscript. E.V. contributed to the analytic strategy, statistical analysis and manuscript development. Both authors contributed to writing the final draft of the manuscript.

\section{References}

1. California Department of Social Services (2007) Eligibility and Issuance Requirements, Food Stamp Program. http:// www.dss.cahwnet.gov/foodstamps/PG841.htm (accessed April 2009).

2. Social Security Administration (2009) Supplemental Security Income (SSI) In California. http://www.ssa.gov/pubs/11125. html (accessed April 2009).

3. California Department of Social Services (2007) California Work Opportunities and Responsibilities to Kids (CalWORKS). http:// www.ladpss.org/dpss/calworks/eligibility.cfm (accessed April 2009).

4. US Department of Agriculture, Food and Nutrition Service (2009) Supplemental Nutrition Assistance Program, Frequently Asked Questions. http://www.fns.usda.gov/snap/ faqs.htm (accessed April 2009).

5. Ver Ploeg M, Mancino L, Lin BH et al. (2007) The vanishing weight gap: trends in obesity among adult food stamp participants (US) (1976-2002). Econ Hum Biol 5, 20-36.

6. Baum C (2007) The Effects of Food Stamps on Obesity. Contractor and Cooperator Report. Murfreesboro, TN: Middle Tennessee State University.

7. Chen Z, Yen ST \& Eastwood DB (2005) Effects of food stamp participation on body weight and obesity. Am J Agric Econ 87, 1167-1173.

8. Dinour LM, Bergen D \& Yeh MC (2007) The food insecurity-obesity paradox: a review of the literature and the role food stamps may play. J Am Diet Assoc 107, 1952-1961. 
9. Gibson D (2003) Food stamp program participation is positively related to obesity in low income women. $J \mathrm{Nutr}$ 133, 2225-2231.

10. Webb AL, Schiff A, Currivan D et al. (2008) Food Stamp Program participation but not food insecurity is associated with higher adult BMI in Massachusetts residents living in low-income neighbourhoods. Public Health Nutr 11, 1248-1255.

11. Zagorsky JL \& Smith PK (2009) Does the US Food Stamp Program contribute to adult weight gain? Econ Hum Biol 7, 246-258.

12. Centers for Disease Control and Prevention (2008) Selfreported concern about food security associated with obesity - Washington, 1995-1999. MMWR Morb Mortal Wkly Rep 52, 840-842.

13. Hanson KL, Sobal J \& Frongillo EA (2007) Gender and marital status clarify associations between food insecurity and body weight. J Nutr 137, 1460-1465.

14. Holben DH \& Pheley AM (2006) Diabetes risk and obesity in food-insecure households in rural Appalachian Ohio. Prev Chronic Dis 3, A82.

15. Martin KS \& Ferris AM (2007) Food insecurity and gender are risk factors for obesity. J Nutr Educ Behav 39, 31-36.

16. Tayie FA \& Zizza CA (2009) Height differences and the associations between food insecurity, percentage body fat and BMI among men and women. Public Health Nutr 12, $1855-1861$.

17. Townsend MS, Peerson J, Love B et al. (2001) Food insecurity is positively related to overweight in women. J Nutr 131, 1738-1745.

18. Wilde PE \& Peterman JN (2006) Individual weight change is associated with household food security status. J Nutr 136, 1395-1400.

19. California Health Interview Survey (2009) CHIS 2007 Methodology Series: Report 4-Response Rates. Los Angeles, CA: UCLA Center for Health Policy Research.

20. California Health Interview Survey (2007) Weighting and Estimation of Variance in the CHIS Public Use Files. Los Angeles, CA: UCLA Center for Health Policy Research.

21. California Health Interview Survey (2009) CHIS 2007 Methodology Series: Report 2 - Data Collection Methods. Los Angeles, CA: UCLA Center for Health Policy Research.

22. US Department of Agriculture (2008) US Household Food Security Survey Module: Six-Item Short Form. Washington, DC: USDA.

23. Jones SJ \& Frongillo EA (2006) The modifying effects of Food Stamp Program participation on the relation between food insecurity and weight change in women. J Nutr 136, 1091-1094.

24. Hellstrom PM, Geliebter A, Naslund E et al. (2004) Peripheral and central signals in the control of eating in normal, obese and binge-eating human subjects. Br J Nutr 92, Suppl. 1, S47-S57.
25. Adams EJ, Grummer-Strawn L \& Chavez G (2003) Food insecurity is associated with increased risk of obesity in California women. J Nutr 133, 1070-1074.

26. Drewnowski A \& Specter SE (2004) Poverty and obesity: the role of energy density and energy costs. Am J Clin Nutr 79, 6-16.

27. Zenk SN, Schulz AJ, Israel BA et al. (2005) Neighborhood racial composition, neighborhood poverty, and the spatial accessibility of supermarkets in metropolitan Detroit. $A m J$ Public Health 95, 660-667.

28. Macdonald L, Cummins S \& Macintyre S (2007) Neighbourhood fast food environment and area deprivation-substitution or concentration? Appetite 49, 251-254.

29. Pearce J, Blakely T, Witten K et al. (2007) Neighborhood deprivation and access to fast-food retailing: a national study. Am J Prev Med 32, 375-382.

30. Cason KL, Cox RH, Burney JL et al. (2002) Do food stamps without education improve the nutrient intake of recipients? Top Clin Nutr 17, 74-82.

31. Hampl JS \& Sass S (2001) Focus groups indicate that vegetable and fruit consumption by food stamp-eligible Hispanics is affected by children and unfamiliarity with non-traditional foods. J Am Diet Assoc 101, 685-687.

32. Wiig K \& Smith C (2009) The art of grocery shopping on a food stamp budget: factors influencing the food choices of low-income women as they try to make ends meet. Public Health Nutr 12, 1726-1734.

33. Betz NE, Mintz L \& Speakmon G (1994) Gender differences in the accuracy of self-reported weight. Sex Roles 30, 543-552.

34. Oliveira A, Ramos E, Lopes C et al. (2009) Self-reporting weight and height: misclassification effect on the risk estimates for acute myocardial infarction. Eur $J$ Public Health 19, 548-553.

35. McAdams MA, Van Dam RM \& Hu FB (2007) Comparison of self-reported and measured BMI as correlates of disease markers in US adults. Obesity (Silver Spring) 15, 188-196.

36. Flegal KM, Carroll MD, Ogden CL et al. (2010) Prevalence and trends in obesity among US adults, 1999-2008. JAMA 303, 235-241.

37. National Center for Chronic Disease Prevention \& Health Promotion (2009) Weight classification by Body Mass Index (BMI). Overweight and Obesity (BMI) - 2007, Prevalence and Trends Data. http://www.cdc.gov/obesity/data/trends. html\#state (accessed March 2010).

38. Hu FB (editor) (2008) Measures of adiposity and body composition. In Obesity Epidemiology, pp. 53-83. New York: Oxford University Press.

39. Azadbakht L, Mirmiran P, Shiva N et al. (2005) General obesity and central adiposity in a representative sample of Tehranian adults: prevalence and determinants. Int J Vitam Nutr Res 75, 297-304. 